\title{
Self-Confidence and Perceptions of Athletic Training Students Following Simulated Experiences: A Mixed-Methods Pilot Study
}

\author{
Hannah L. Stedge \\ Weber State University, hannahstedge@weber.edu \\ Valerie Herzog \\ Weber State University, ValerieHerzog@weber.edu
}

Follow this and additional works at: https://nsuworks.nova.edu/ijahsp

Part of the Sports Sciences Commons

\section{Recommended Citation}

Stedge HL, Herzog V. Self-Confidence and Perceptions of Athletic Training Students Following Simulated Experiences: A Mixed-Methods Pilot Study. The Internet Journal of Allied Health Sciences and Practice. 2021 Jan 01;19(3), Article 5.

This Manuscript is brought to you for free and open access by the College of Health Care Sciences at NSUWorks. It has been accepted for inclusion in Internet Journal of Allied Health Sciences and Practice by an authorized editor of NSUWorks. For more information, please contact nsuworks@nova.edu. 


\title{
Self-Confidence and Perceptions of Athletic Training Students Following Simulated Experiences: A Mixed-Methods Pilot Study
}

\begin{abstract}
Purpose: Athletic training clinical education provides students with a variety of real-life patient encounters under the supervision of a credentialed athletic trainer. However, clinical education experiences may not allow for all students to practice more invasive or less common skills such as rectal thermometry. The purpose of this study was two-fold: 1) determine the effect of a series of low to high-fidelity simulated rectal thermometry experiences on athletic training students' self-confidence scores; and 2) through a phenomenological qualitative approach, explore athletic training students' perceptions following the simulated rectal thermometry experiences. Method: This study used a quasi-experimental, mixed methods, one-group repeated measures design. Participants were nine first year professional Master of Athletic Training students who completed four simulated experiences on the skill of rectal thermometry. The outcome measures were The Athletic Trainer's Self-Confidence Scale (ATSCS) and qualitative semistructured open-ended interviews. Results: Friedman's ANOVA revealed a statistically significant improvement from the participant's baseline ATSCS scores to the last post-test scores. We identified three major themes following qualitative interviews: 1) Perception changes before and after participation; 2) Benefits of a series of four simulations; 3) Explanations for the improvements in confidence and competence. Conclusions: A series of simulated learning activities using high-fidelity and standardized patient interactions can help improve athletic training students' self-confidence. Though future research is needed, athletic training education programs should consider implementing simulated experiences to equip athletic training students to transition to practice.
\end{abstract}

\section{Author Bio(s)}

Hannah L. Stedge, MS, LAT, ATC, is an Instructor in the Department of Athletic Training in the Dumke College of Health Professions at Weber State University in Ogden, UT. She is also a licensed athletic trainer in the state of Utah.

Valerie W. Herzog, EdD, LAT, ATC, is Chair of the Department of Athletic Training in the Dumke College of Health Professions at Weber State University in Ogden, UT. She is also a licensed athletic trainer in the state of Utah.

\section{Acknowledgements}

We would like to thank Thomas Cappaert, PhD, ATC, CSCS for his consultation on the statistical analysis in this study. 


\title{
IIAAHSP \\ The Internet Journal of Allied Health Sciences and Practice \\ Dedicated to allied health professional practice and education \\ Vol. 19 No. 3 ISSN 1540-580X
}

\section{Self-Confidence and Perceptions of Athletic Training Students Following Simulated Experiences: A Mixed-Methods Pilot Study}

\author{
Hannah L. Stedge \\ Valerie Herzog \\ Weber State University \\ United States
}

\begin{abstract}
Purpose: Athletic training clinical education provides students with a variety of real-life patient encounters under the supervision of a credentialed athletic trainer. However, clinical education experiences may not allow for all students to practice more invasive or less common skills such as rectal thermometry. The purpose of this study was two-fold: 1) determine the effect of a series of low to high-fidelity simulated rectal thermometry experiences on athletic training students' self-confidence scores; and 2) through a phenomenological qualitative approach, explore athletic training students' perceptions following the simulated rectal thermometry experiences. Method: This study used a quasi-experimental, mixed methods, one-group repeated measures design. Participants were nine first year professional Master of Athletic Training students who completed four simulated experiences on the skill of rectal thermometry. The outcome measures were The Athletic Trainer's Self-Confidence Scale (ATSCS) and qualitative semistructured open-ended interviews. Results: Friedman's ANOVA revealed a statistically significant improvement from the participant's baseline ATSCS scores to the last post-test scores. We identified three major themes following qualitative interviews: 1) Perception changes before and after participation; 2) Benefits of a series of four simulations; 3) Explanations for the improvements in confidence and competence. Conclusions: A series of simulated learning activities using high-fidelity and standardized patient interactions can help improve athletic training students' self-confidence. Though future research is needed, athletic training education programs should consider implementing simulated experiences to equip athletic training students to transition to practice.
\end{abstract}

Keywords: High-fidelity simulation, standardized patients, transition to practice, self-confidence 


\section{INTRODUCTION}

Athletic training education programs utilize clinical education experiences for their students to learn and master various clinical proficiencies. Formal clinical education in athletic training began around the 1970 s. $^{1}$ While it has evolved since that date, clinical education still provides a unique way for students to connect didactic theory to clinical practice in a supervised manner. ${ }^{2}$ During clinical education, athletic training students are given opportunities to observe and engage in real-life experiences under the direction of a credentialed clinician. ${ }^{2}$

Exertional heat illnesses (EHIs) are common in sport, and athletic trainers must be prepared to recognize and manage these conditions. The gold standard for evaluating core body temperature is rectal thermometry. ${ }^{3,4}$ In 2011 , the National Athletic Trainer's Association (NATA) educational competencies were revised to include rectal thermometry in athletic training education. ${ }^{5}$ Additionally, the latest position statement from the NATA on the treatment of exertional heat illnesses, states performing rectal thermometry is needed in all situations where exertional heat illness is a possibility. ${ }^{3}$ Research shows that more patient encounters in clinical education can improve a newly credentialed athletic trainer's transition to practice. ${ }^{6}$ However, athletic training students may not have patient encounters involving more invasive or less common techniques such as rectal thermometry. A study conducted in 2017 identified that $86.9 \%$ of twenty-five certified athletic trainers used methods other than rectal thermometry to identify heat illnesses. ${ }^{7}$ These athletic trainers cited a lack of authentic practice in their education programs as the major contributing factor. ${ }^{7}$ Regardless, the 2020 Standards for Accreditation of Professional Athletic Training Programs require athletic training education programs prepare their graduates to identify heat illnesses by performing rectal thermometry. ${ }^{8}$ Given the possibility of not having authentic practice, the 2020 standards also allow for the use of simulation technology to supplement clinical proficiencies where direct patient care is not possible. ${ }^{8}$

Athletic training education programs need to prepare students to identify and manage life-threatening conditions such as EHS. However, if some athletic training students do not have opportunities to practice rectal thermometry during their clinical education, they may lack confidence when performing it in clinical practice. The Athletic Trainer's Self-Confidence Scale (ATSCS) is one method for assessing athletic training student self-confidence in managing EHls. ${ }^{9}$ The ATSCS has satisfactory internal consistency and validity (Pearson's $r$ correlation $r=.19-.79$ ) and high reliability (Cronbach coefficient alphas $a=.82$ ). ${ }^{9}$ The ATSCS recently evaluated certified athletic trainer's self-confidence levels in managing exertional heat illnesses. ${ }^{9}$ However, this tool has not yet evaluated student athletic trainers' confidence levels following simulated EHI learning experiences.

\section{Simulated Learning in Athletic Training}

There are varying levels of simulation education in the literature. These levels are known as fidelity, which pertains to the amount of realism a simulation provides. ${ }^{10}$ Low-fidelity simulation is used throughout health professions education programs because it utilizes inexpensive task trainers such as plastic manikin models. ${ }^{11}$ Mid-fidelity simulation is accomplished through the use of live simulated or standardized patients. Standardized patients (SPs) are individuals formally trained in how to portray an injury or illness consistently in a role-playing educational scenario. ${ }^{10}$ Finally, high-fidelity simulation uses an electronic, computerized patient such as Laerdal's SimMan manikin equipped with software used to assess student competency. ${ }^{12}$ High-fidelity manikins are able to provide students with authentic practice in critical thinking, decision making, and emergency care. ${ }^{12}$ The use of simulation for learning less common and invasive skills could help improve student's self- confidence and competence when they need to perform those skills in a real-life setting. The repeatability that simulated experiences can provide may help improve cognitive learning as well as promote reflection. ${ }^{13}$ For example, following a simulated experience, a student has the opportunity to obtain feedback and then practice with their instructor prior to the next simulated experience. To support this, Paloncy et al found a debriefing session following high-fidelity simulation was helpful to improve athletic training students' competence in performing cardiovascular care during a subsequent simulation session two weeks later. ${ }^{14}$

There is currently a lack of research on high-fidelity simulation in athletic training education curriculum. ${ }^{12,15}$ However, the literature does support the use of high-fidelity simulation for teaching and evaluating students' emergency cardiac skills. ${ }^{16-18}$ Other recent studies have demonstrated that mid-fidelity simulation utilizing standardized patients is useful to assess and improve athletic training students' psychosocial and referral skills, and confidence. ${ }^{19-23}$ Additional literature identifies standardized patients improve an athletic trainer's ability to translate a new skill into their clinical practice. ${ }^{24}$ Lastly, Kinslow et al25 found a hybrid simulation involving SPs was effective for improving athletic training students' knowledge of assessing exertional heat stroke (EHS). These authors found the use of a standardized patient (SP) combined with a low-fidelity rectal model provided a realistic, yet low-risk environment for students to learn. ${ }^{25}$

While the amount of quantitative literature on simulated learning in athletic training is limited, qualitative research on this area is even less. Currently, only two studies have looked at athletic training students' perceptions following SP encounters. ${ }^{10,} 20$ 
Furthermore, only one study assessed pre-athletic training students' self-confidence following a high-fidelity manikin simulation for anaphylactic shock. ${ }^{26}$

Little literature exists on the effects of simulated education on athletic training students' self-confidence. Therefore, the purpose of this study was two-fold: 1) determine the effect of a series of low to high-fidelity simulated rectal thermometry experiences on athletic training students' ATSCS scores; and 2) through a phenomenological qualitative approach, explore athletic training students' perceptions following the simulated rectal thermometry experiences. This study also served as a pilot-study for a larger, repeated measures cohort study.

\section{METHODS}

This pilot study was conducted at Weber State University and was approved by the University's Institutional Review Board (protocol number: 19_HP_002). A quasi-experimental, mixed methods, one-group repeated measures design was used for this study.

\section{Participants}

A purposeful convenience sample strategy was implemented for this study. The sample from this study was recruited from a foundational athletic training (AT) course in which students learn how to recognize and manage EHIs and other environmental conditions. Participants were all first semester students in the professional Master of Science in Athletic Training program at Weber State University. Nine students, ages 21-30 years old (23.5 \pm 2.7 years; one male, eight females; 1 Asian, 1 Pacific Islander, 1 African American, 6 white Caucasian) consented to participate in this study. Six participants completed all six administrations of the ATSCS. Four participants, ages 21-23 years old (22.25 \pm 0.96 years; four white Caucasian females) participated in follow-up qualitative interviews. None of the participants had any prior experience with rectal thermometry.

\section{Intervention}

Each participant received pre-simulation education on recognizing and managing EHls.

Simulation 1: Rectal thermometry on a low-fidelity plastic rectum model.

Simulation 2: Self-insertion of a rectal thermometer followed by a workout or passive heating via sitting in a sauna.

Simulation 3: Rectal thermometry on a full-sized, high-fidelity simulation manikin.

Simulation 4: Rectal thermometry on a standardized patient.

\section{Materials}

For each of the four simulation experiences, participants used a Data Therm II continuous temperature rectal monitor with a 78" long probe. Simulation 3 used a high-fidelity Laerdal SimMan, a pre-programmed, computerized manikin capable of portraying several emergency scenarios. This SimMan was equipped with voice communication where a peer portrayed the voice of the patient (manikin). For simulation 4, one professionally trained standardized patient was employed for all students to individually perform rectal thermometry on.

\section{Outcome Measures}

The ATSCS was administered to all participants at several time points to establish the level of their self-confidence. This is a 9item survey utilizing a 7-point Likert scale ranging from $1=$ strongly agree to $7=$ strongly disagree. ${ }^{9}$ For each of the 9 items, participants were asked to indicate their perceived self-confidence with answer choices of: $1=$ strongly agree, $2=$ agree, $3=$ somewhat agree, 4 = undecided, 5 = somewhat disagree, 6 = disagree, $7=$ strongly disagree. Survey items are listed in Table 1.

Table 1: Athletic Trainer's Self-Confidence Scale (ATSCS)

\begin{tabular}{|l|l|}
\hline$\#$ & \multicolumn{1}{c|}{ Question Item } \\
\hline 1 & I can always manage to solve difficult problems when working with an exertional heat illness patient. \\
\hline 2 & If a heat illness emergency arises, I can identify the problem in a timely manner, so no one is harmed. \\
\hline 3 & I can establish return to activity goals for individuals that have recently encountered a heat illness. \\
\hline 4 & $\begin{array}{l}\text { I am confident that I can efficiently respond to unexpected exertional heat illness events and be able to recognize, treat, } \\
\text { and prevent them in a proper amount of time. }\end{array}$ \\
\hline 5 & I know the proper way to administer a rectal thermometer. \\
\hline 6 & I can create a heat illness action plan for patients' practices and games. \\
\hline 7 & I remain calm if a patient were facing a life- threatening heat illness condition because I can rely on my coping skills \\
\hline
\end{tabular}


\begin{tabular}{|l|l|}
\hline 8 & $\begin{array}{l}\text { When confronted with a patient exhibiting signs/symptoms of heat illness, I know how to correctly use the rectal } \\
\text { thermometer to determine if the patient is suffering from exertional heat stroke and when to remove them from an ice } \\
\text { bath based on their core temperature. }\end{array}$ \\
\hline 9 & If a patient is in trouble, I can think of an emergency plan. \\
\hline
\end{tabular}

We utilized open-ended interview questions to explore students' perceptions of the simulated rectal thermometry experiences. Each of the participants were asked eight interview questions (Table 2).

Table 2: Follow-up Interview Questions

\begin{tabular}{|l|l|}
\hline$\#$ & \multicolumn{1}{c|}{ Questions } \\
\hline 1 & $\begin{array}{l}\text { Tell me about your experiences this semester with the } 4 \text { simulated experiences. What positive experiences did you gain? } \\
\text { What negative experiences did you have? }\end{array}$ \\
\hline 2 & $\begin{array}{l}\text { Please describe your perceptions of the experiences, reflecting on your thoughts prior to the first experience, and how } \\
\text { you feel now upon completion. }\end{array}$ \\
\hline 3 & $\begin{array}{l}\text { How did your opinions and attitudes regarding performing rectal thermometry change throughout the } 4 \text { simulated } \\
\text { experiences? }\end{array}$ \\
\hline 4 & Talk to me about any benefits or improvements (if any) that each of the simulated experiences had on you. \\
\hline 5 & What was your attitude regarding performing rectal thermometry now? \\
\hline 6 & How do you perceive your competence in rectal thermometry has changed (if at all)? \\
\hline 7 & How do you perceive your confidence in performing rectal thermometry has changed (if at all)? \\
\hline 8 & $\begin{array}{l}\text { How do you perceive these experiences will influence you (positively or negatively) when you transition to a clinical } \\
\text { practice as a credentialed athletic trainer? }\end{array}$ \\
\hline
\end{tabular}

\section{Procedures}

On the first day of class, participants filled out the baseline test for the ATSCS. Participants completed the ATSCS on Qualtrics $\mathrm{XM}^{\mathrm{TM}}$ Experience Management Software using their own personal computers in class. The following two weeks of class were focused on pre-simulation didactic education on EHIs. Over the remainder of the semester, students participated in 4 simulated experiences as class laboratory exercises. Each simulation experience was part of a 50-minute laboratory period. For each simulation experience, participants were provided with the following instructions: measure and mark off $15 \mathrm{~cm}$ on the rectal thermistor probe, clean the probe with an alcohol wipe, apply lubricant to it, then insert the probe $15 \mathrm{~cm}$ into the rectum. Participants were then instructed to attach the probe to the temperature monitor and record the core body temperature on a provided sheet. Lastly, participants removed the probe, cleaned it again, and then observed their partner perform the same steps. Each participant received individual feedback from the instructor as well as a reflection session in the following class period. The course learning outcome associated with these simulations was: "Upon successful completion of this course, students will be expected to identify and manage environmental illnesses such as EHIs".

Simulation 1 occurred in the fourth week of the semester. Participants were provided with a low-fidelity, plastic rectum model and instructions and demonstration for how to perform rectal thermometry. Participants were given multiple practice attempts as well as opportunities to observe their partner performing the skill. Immediately after this experience, the same day, participants responded to the first ATSCS post-test.

Simulation 2 was completed one week after simulation 1. Before the simulation, each participant completed the ATSCS reflecting their current self-confidence. For simulation 2, participants were given written and verbal instructions on self-insertion of the rectal thermometer. Participants went into a private room with gloves and a sterile rectal thermistor and performed the self-insertion. Participants then completed a workout or passive heating via sitting in a sauna with the thermistor in place. After completing the heating, participants removed the thermistor, read, and recorded their rectal temperature. Immediately after completing the selfinsertion simulation, the same day, participants completed post-test 2 of the ATSCS.

After the first two simulated experiences, participants underwent additional didactic training to prepare them to interact with and take a patient history on high-fidelity simulation manikins and SPs. We identified minor participant survey fatigue for the ATSCS between the first post-test to the second pre-test, so we decided to eliminate further pre-tests of the survey, and only implement the post-tests. 
Simulation 3 occurred two months after simulation 2 and involved performing rectal thermometry on a full-sized, high-fidelity simulation manikin. Participants met in the University's simulation lab and were instructed to come prepared with a studentdeveloped script for communicating with the patient (manikin) throughout the procedure. Participants then had individual opportunities to practice inserting the rectal thermometer on the SimMan. The focus of this simulation was on communication with the patient, proper draping during the procedure, and rolling the patient onto their side. The student's partner spoke on behalf of the patient and provided their partner with feedback on their communication and technique. Immediately following this, on the same day, the participants completed post-test 3 of the ATSCS.

One week later, participants underwent simulation 4 . The SP was in a private room with the instructor observing. Participants were prepared to communicate with the SP via their prepared, memorized script. When the participant was directed to do so, they entered the room, introduced themselves, explained, and then performed rectal thermometry on the SP. When the procedure was completed, the SP gave the participant feedback on both their technique and communication. The instructor then provided additional feedback on both patient communication and technique. Immediately after this experience, on the same day, participants completed post-test 4 of the ATSCS (See Figure).

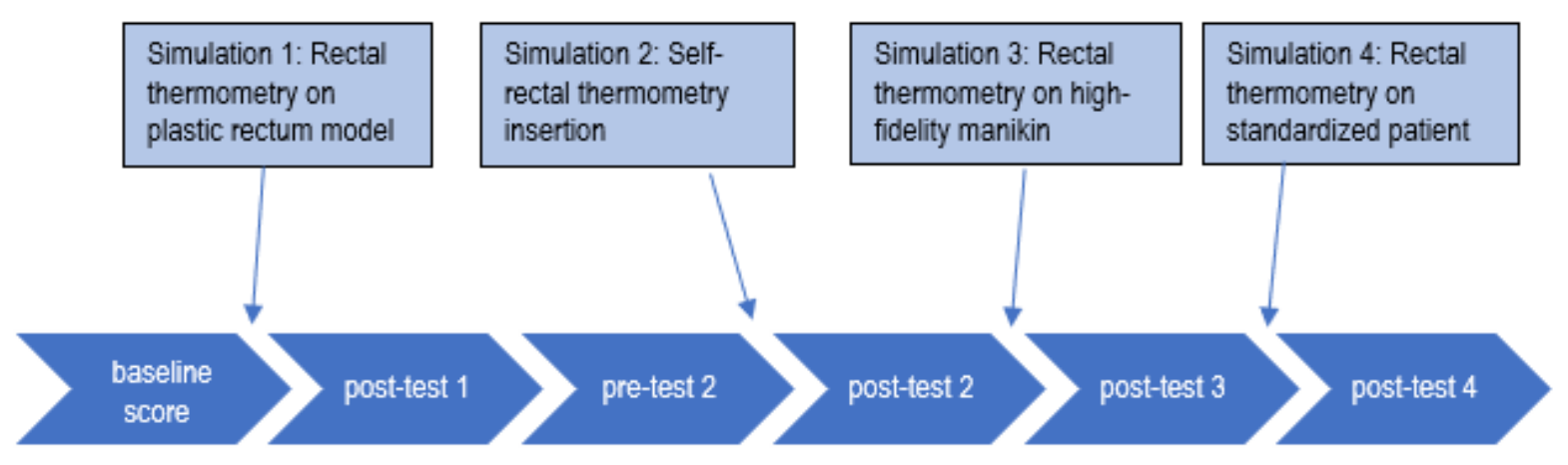

Figure. Flow Diagram

In the following semester, we emailed each of the participants requesting participation in additional semi-structured follow-up interviews. All interviews took place over the phone with one of the authors (H.S.) in a private office. Interview \#1 (with Jenny) occurred on March 27, 2020, and lasted 18 minutes; interview \#2 (with Beth) occurred on March 27, 2020, and lasted 16 minutes; interview \#3 (with Shelley) occurred on April 1, 2020, and lasted 17 minutes; and interview \#4 (with Cass) occurred on April 2 , 2020, and lasted 18 minutes.

\section{Data Analysis}

Quantitative and qualitative data were gathered for this study. Quantitative data were analyzed using SPSS version 25 (IBM Corporation, Armonk, NY, USA). Due to the ordinal nature of the data, the Friedman's ANOVA and multiple regression were selected. The Wilcoxon Post-hoc Test was used to identify the specific areas of statistical significance.

An audio recording of each of the 4 phone interviews was made, transcribed verbatim, and then each participant was de-identified with a pseudonym. Qualitative data were analyzed through an inductive approach, which is a 3-step process. ${ }^{27}$ First, the text transcriptions were printed and read through. On the second read, codes were attached to the data. Lastly, the codes were combined into categories that were further analyzed to identify themes. Analysis concluded when all themes accurately reflected the views and perceptions of the participants. Initial coding was conducted by one author (H.S.). Codes and themes were then verified by the second author (V.H.) by analyzing the interview data independently.

\section{Trustworthiness}

To ensure trustworthiness of the qualitative data, interview questions were peer reviewed and reviewed by an external reviewer independent from this study who was also trained in qualitative analysis. We also performed member checking by emailing both the typed transcripts as well as the audio recording to each participant to confirm accuracy. We also sent the themes and interpretations to each participant to ensure their opinions and thoughts were accurately portrayed. 


\section{RESULTS}

\section{Quantitative Results}

A total of six participants completed every administration of the ATSCS. A Friedman's ANOVA reported statistically significant improvements from the participant's baseline ATSCS scores compared to the last post-test scores for each of the nine ATSCS question items (Table 3).

Table 3: Result of Friedman's ANOVA with empty data eliminated $(\mathrm{N}=6)$

\begin{tabular}{|c|c|c|c|c|c|}
\hline $\begin{array}{c}\text { ATSCS } \\
\text { Questions }\end{array}$ & $\begin{array}{c}\text { ATSCS } \\
\text { test }\end{array}$ & Mean & SD & $\mathrm{X}^{2}$ & P-value \\
\hline \multirow[t]{2}{*}{1} & Baseline & 5.67 & .816 & \multirow[b]{2}{*}{26.969} & \multirow[b]{2}{*}{0.000} \\
\hline & Post-test 4 & 1.17 & .408 & & \\
\hline \multirow[t]{2}{*}{2} & Baseline & 5.33 & .816 & \multirow[b]{2}{*}{26.154} & \multirow[b]{2}{*}{0.000} \\
\hline & Post-test 4 & 1.17 & .408 & & \\
\hline \multirow[t]{2}{*}{3} & Baseline & 6.17 & .753 & \multirow[b]{2}{*}{26.735} & \multirow[b]{2}{*}{0.000} \\
\hline & Post-test 4 & 1.17 & .408 & & \\
\hline \multirow[t]{2}{*}{4} & Baseline & 5.83 & .408 & \multirow[b]{2}{*}{25.734} & \multirow[b]{2}{*}{0.000} \\
\hline & Post-test 4 & 1.17 & .408 & & \\
\hline \multirow[t]{2}{*}{5} & Baseline & 6.17 & 1.602 & \multirow[b]{2}{*}{24.830} & \multirow[b]{2}{*}{0.000} \\
\hline & Post-test 4 & 1.00 & .000 & & \\
\hline \multirow[t]{2}{*}{6} & Baseline & 6.43 & .535 & \multirow[b]{2}{*}{31.345} & \multirow[b]{2}{*}{0.000} \\
\hline & Post-test 4 & 1.29 & .488 & & \\
\hline \multirow[t]{2}{*}{7} & Baseline & 3.33 & 1.633 & \multirow[b]{2}{*}{12.582} & \multirow[b]{2}{*}{0.028} \\
\hline & Post-test 4 & 1.00 & .000 & & \\
\hline \multirow[t]{2}{*}{8} & Baseline & 6.33 & 1.211 & \multirow[b]{2}{*}{27.618} & \multirow[b]{2}{*}{0.000} \\
\hline & Post-test 4 & 1.00 & .000 & & \\
\hline \multirow[t]{2}{*}{9} & Baseline & 4.50 & 1.225 & \multirow[b]{2}{*}{25.239} & \multirow[b]{2}{*}{0.000} \\
\hline & Post-test 4 & 1.17 & .408 & & \\
\hline
\end{tabular}

Nine participants completed 3 of the administrations of the ATSCS survey. Therefore, we also ran Friedman's ANOVA on the data with multiple regression to replace the missing data from "post-test 1," "post-test 3," and "post-test 4." This also reported statistically significant improvements from baseline compared to the last post-test scores for all nine items (Table 4).

Table 4: Friedman's ANOVA with multiple regression data ( $\mathrm{N}=9$ )

\begin{tabular}{|c|c|c|c|c|c|}
\hline $\begin{array}{c}\text { ATSCS } \\
\text { Questions }\end{array}$ & $\begin{array}{c}\text { ATSCS } \\
\text { test }\end{array}$ & Mean & SD & $\mathrm{X}^{2}$ & P-value \\
\hline \multirow{2}{*}{1} & Baseline & 4.78 & 1.716 & \multirow[b]{2}{*}{20.830} & \multirow[b]{2}{*}{0.001} \\
\hline & Post-test 4 & 1.78 & 1.093 & & \\
\hline \multirow[t]{2}{*}{2} & Baseline & 4.67 & 1.414 & \multirow[b]{2}{*}{30.126} & \multirow[b]{2}{*}{0.000} \\
\hline & Post-test 4 & 1.44 & .527 & & \\
\hline \multirow[t]{2}{*}{3} & Baseline & 5.22 & 1.856 & \multirow[b]{2}{*}{21.444} & \multirow[b]{2}{*}{0.001} \\
\hline & Post-test 4 & 1.56 & .726 & & \\
\hline \multirow[t]{2}{*}{4} & Baseline & 4.78 & 1.787 & \multirow[b]{2}{*}{23.872} & \multirow[b]{2}{*}{0.000} \\
\hline & Post-test 4 & 1.44 & .527 & & \\
\hline \multirow[t]{2}{*}{5} & Baseline & 5.44 & 1.944 & \multirow[b]{2}{*}{33.726} & \multirow[b]{2}{*}{0.000} \\
\hline & Post-test 4 & 1.11 & .333 & & \\
\hline \multirow[t]{2}{*}{6} & Baseline & 5.56 & 1.810 & \multirow[b]{2}{*}{31.607} & \multirow[b]{2}{*}{0.000} \\
\hline & Post-test 4 & 1.44 & .527 & & \\
\hline \multirow[t]{2}{*}{7} & Baseline & 3.11 & 1.453 & \multirow[b]{2}{*}{15.228} & \multirow[b]{2}{*}{0.009} \\
\hline & Post-test 4 & 1.22 & .441 & & \\
\hline \multirow[t]{2}{*}{8} & Baseline & 5.78 & 1.716 & \multirow[b]{2}{*}{35.076} & \multirow{3}{*}{0.000} \\
\hline & Post-test 4 & 1.22 & .441 & & \\
\hline 9 & Baseline & 4.11 & 1.691 & & \\
\hline
\end{tabular}




\begin{tabular}{l|l|l|l|l|} 
Post-test 4 & 1.33 & .500 & 29.205 & 0.000 \\
\hline
\end{tabular}

The Wilcoxon Post-hoc Test identified the specific areas of statically significant differences for each of the nine items (Table 5).

Table 5: Results of the Wilcoxon post-hoc test: $(\mathrm{N}=9)$

\begin{tabular}{|c|c|c|c|}
\hline $\begin{array}{c}\text { ATSCS } \\
\text { Questions }\end{array}$ & \multicolumn{2}{|l|}{ Mean difference between tests } & P-level \\
\hline \multirow{3}{*}{1} & Pre-test 2 & Post-test 2 & 0.025 \\
\cline { 2 - 4 } & Baseline & Post-test 4 & 0.020 \\
\hline \multirow{3}{*}{2} & Baseline & Post-test 1 & 0.011 \\
\cline { 2 - 4 } & Baseline & Post-test 4 & 0.011 \\
\hline \multirow{4}{*}{4} & Baseline & Post-test 1 & 0.011 \\
\cline { 2 - 4 } & Post-test 3 & Post-test 4 & 0.038 \\
\cline { 2 - 4 } & Baseline & Post-test 4 & 0.010 \\
\hline \multirow{4}{*}{5} & Baseline & Post-test 1 & 0.011 \\
\cline { 2 - 4 } & Post-test 1 & Pre-test 2 & 0.023 \\
\cline { 2 - 4 } & Baseline & Post-test 4 & 0.011 \\
\hline \multirow{4}{*}{6} & Baseline & Post-test 1 & 0.011 \\
\cline { 2 - 4 } & Pre-test 2 & Post-test 2 & 0.015 \\
\cline { 2 - 4 } & Baseline & Post-test 4 & 0.007 \\
\cline { 2 - 4 } & Baseline & Post-test 1 & 0.011 \\
\cline { 2 - 4 } & Pre-test 2 & Post-test 2 & 0.014 \\
\hline \multirow{3}{*}{7} & Baseline & Post-test 4 & 0.011 \\
\hline \multirow{3}{*}{8} & Baseline & Post-test 1 & 0.027 \\
\cline { 2 - 4 } & Baseline & Post-test 4 & 0.017 \\
\hline & Baseline & Post-test 1 & 0.011 \\
\cline { 2 - 4 } & Pre-test 2 & Post-test 2 & 0.004 \\
\cline { 2 - 4 } & Baseline & Post-test 4 & 0.011 \\
\hline \multirow{4}{*}{9} & Baseline & Post-test 1 & 0.011 \\
\cline { 2 - 4 } & Pre-test 2 & Post-test 2 & 0.034 \\
\cline { 2 - 4 } & Post-test 3 & Post-test 4 & 0.046 \\
\cline { 2 - 4 } & Baseline & Post-test 4 & 0.011 \\
\hline \multirow{4}{*}{} & & & \\
\hline
\end{tabular}

\section{Qualitative Results}

We identified three major themes: 1) Perception changes before and after participation; 2) Benefits of a series of four simulations; and 3) Explanations for the improvements in confidence and competence (Table 6).

Table 6: Student perceptions (continued on next page)

\begin{tabular}{|c|c|c|}
\hline Theme & Code & Quotes \\
\hline \multirow{8}{*}{$\begin{array}{l}\text { Perceptions } \\
\text { before } \\
\text { participation }\end{array}$} & \multirow[t]{8}{*}{ Uncomfortable } & $\begin{array}{l}\text { J: "[l thought performing rectal thermometry was] like a weird or uncomfortable situation in } \\
\text { my head." }\end{array}$ \\
\hline & & $\begin{array}{l}\text { J: "It's not perceived as like a comfortable [situation], it's more like an awkward situation } \\
\text { that you think of and not wanting to ever have to experience that." }\end{array}$ \\
\hline & & S: "[l was] thinking you know this is just gonna be really awkward." \\
\hline & & $\begin{array}{l}\text { C: "I think it definitely like took me off guard to begin with that we were even going to do } \\
\text { this." }\end{array}$ \\
\hline & & J: "I was nervous because I thought it would be awkward or uncomfortable" \\
\hline & & $\begin{array}{l}\text { S: "I was a little worried, so I was like 'I wonder what this is gonna feel like.' I guess I } \\
\text { shouldn't say worried, I was just like slightly concerned, made me a little anxious about it." }\end{array}$ \\
\hline & & C: "We were all very uncomfortable at first..." \\
\hline & & B: "It could seem kind of daunting for someone to perform." \\
\hline
\end{tabular}




\begin{tabular}{|c|c|c|}
\hline & \multirow{2}{*}{$\begin{array}{l}\text { Complex and } \\
\text { Daunting }\end{array}$} & B: "At the beginning it seemed quite complex." \\
\hline & & S: "we were all kind of freaking out about it I guess" \\
\hline \multirow{7}{*}{$\begin{array}{l}\text { Perceptions } \\
\text { after } \\
\text { participation }\end{array}$} & \multirow{2}{*}{$\begin{array}{l}\text { Not } \\
\text { uncomfortable }\end{array}$} & J: "It was not as hard or as weird as I perceived it to be previous to that experience." \\
\hline & & $\begin{array}{l}\text { S: "... after we did it, I was like this really isn't that bad. [lt] definitely gave me an upper } \\
\text { hand if I have to use it in an actual clinical setting" }\end{array}$ \\
\hline & \multirow{2}{*}{ Easier } & S: "It just, it just got easier." \\
\hline & & C: "Step by step, it got a lot easier for us." \\
\hline & Beneficial & $\begin{array}{l}\text { B: "I perceive [rectal thermometry] to be really beneficial and very positive in a learning } \\
\text { environment." }\end{array}$ \\
\hline & \multirow[t]{2}{*}{ Necessary } & $\begin{array}{l}\text { S: "I don't feel like it's really that big of a deal and if it's gonna save somebody's life, how I } \\
\text { feel doesn't matter." }\end{array}$ \\
\hline & & C: "If we don't know how to do this, like, something bad is going to happen in the future." \\
\hline \multirow[t]{11}{*}{$\begin{array}{l}\text { Benefits of four } \\
\text { simulations }\end{array}$} & \multirow[t]{3}{*}{$\begin{array}{l}\text { Progressive } \\
\text { challenge }\end{array}$} & $\begin{array}{l}\text { B: "I think that just the [multiple simulations] are not just like throwing us in and just kind of } \\
\text { saying 'here you go, figure it out." }\end{array}$ \\
\hline & & J: "Just being able to do it over and over again helps a lot with learning." \\
\hline & & $\begin{array}{l}\text { C: "...being able to have the four simulations and kind of go from bottom up, was a really } \\
\text { good experience to be able to kind of like ease into it." }\end{array}$ \\
\hline & \multirow{2}{*}{$\begin{array}{l}\text { Real life } \\
\text { experience }\end{array}$} & $\mathrm{J}$ : "[The self-insertion] also gave us the actual feeling of what it is to be a patient." \\
\hline & & $\begin{array}{l}\text { S: "The benefit for self-insertion was...to relate with the athlete when they actually have [it } \\
\text { done] in the field." }\end{array}$ \\
\hline & \multirow{3}{*}{$\begin{array}{l}\text { Patient } \\
\text { interaction } \\
\text { skills }\end{array}$} & $\begin{array}{l}\text { J: "I would definitely say that [in the third simulation I learned] bedside manner... what to } \\
\text { say and how to properly do it." }\end{array}$ \\
\hline & & $\begin{array}{l}\text { B: "I would feel like I could explain the procedure and make the patient at ease before I } \\
\text { performed it." }\end{array}$ \\
\hline & & $\begin{array}{l}\text { C: "I think the positive was...being able to better explain to somebody else that this isn't } \\
\text { something to be scared about." }\end{array}$ \\
\hline & \multirow[t]{3}{*}{ Feedback } & $\begin{array}{l}\text { J: "...the standardized patient...gave so much feedback [that] I feel confident that...I'd be } \\
\text { able to perform [rectal thermometry]." }\end{array}$ \\
\hline & & $\begin{array}{l}\text { B: "At the end, the standardized the standardized patient provided feedback and I think } \\
\text { that that feedback would positively impact my practice." }\end{array}$ \\
\hline & & $\begin{array}{l}\text { C: "I felt really confident afterwards because [my professor] and the standardized patient } \\
\text { both gave me very good feedback." }\end{array}$ \\
\hline \multirow{7}{*}{$\begin{array}{l}\text { Improvements in } \\
\text { confidence and } \\
\text { competence }\end{array}$} & \multirow[t]{3}{*}{$\begin{array}{l}\text { Live patient } \\
\text { confidence }\end{array}$} & $\begin{array}{l}\text { J: "I would feel more confident and able to do [rectal thermometry] because l've done it on } \\
\text { a live patient as well as myself now." }\end{array}$ \\
\hline & & $\begin{array}{l}\text { B: "I would feel comfortable, performing it and I would feel like I could explain the } \\
\text { procedure and make the patient at ease before I performed it." }\end{array}$ \\
\hline & & $\begin{array}{l}\text { C: "I don't feel like l'd be as confident as I am right now if I didn't get to do it on a real } \\
\text { person. I feel confident in knowing how to insert a rectal thermometer, how to read, and } \\
\text { how to prepare a patient physically and mentally..." }\end{array}$ \\
\hline & \multirow{2}{*}{$\begin{array}{l}\text { Competence in } \\
\text { rectal } \\
\text { thermometry }\end{array}$} & S: "...it really just wasn't that hard. Like it wasn't a hard task."” \\
\hline & & $\begin{array}{l}\text { C: "It made me feel like I was prepared to leave the classroom and know what I was } \\
\text { doing." }\end{array}$ \\
\hline & \multirow[t]{2}{*}{$\begin{array}{l}\text { Preparation for } \\
\text { clinical practice }\end{array}$} & $\begin{array}{l}\text { J: "I came away from each lab a little more prepared and educated on how to insert it for } \\
\text { an actual situation. It has prepared me for what I have to do eventually in my own clinical } \\
\text { practice." }\end{array}$ \\
\hline & & $\begin{array}{l}\text { S: "At my clinical sites I've noticed...they're not comfortable with the procedure...and I } \\
\text { think it gives me a leg up because I can do it and...I can use this technique to take better } \\
\text { care of the athletes." }\end{array}$ \\
\hline
\end{tabular}


C: "I'm prepared...to go out in the field and be ready to do it, or even teach somebody else...this experience has helped me to be prepared to...sit down with the team...and educate them; whether it be with rectal thermometry or with something else."

\section{Three Major Themes}

\section{Perception Changes Before and After Participation}

Participants were nervous before participating in rectal thermometry and perceived the task as uncomfortable and daunting. One student stated, "I was nervous because I thought it would be awkward or uncomfortable (Jenny)." Another student remembered thinking, "at the beginning, it seemed quite complex (Beth)." However, regarding questions on participants' perceptions after completing the final simulation (rectal thermometry on an SP), they had noticeable changes. Participants now expressed comfort and ease in performing rectal thermometry. "It was not as hard or as weird as I perceived it to be...(Jenny)" and "it just got easier (Shelley)" were common responses. Additionally, the participants all commented that rectal thermometry was a necessary skill for athletic trainers. "After that, I just really understood the importance (Beth)" and "If we don't know how to do this, ...something bad is going to happen in the future (Cass)" were noted.

\section{Benefits of a Series of Four Simulations}

Each of the participants expressed appreciating the series of four simulated experiences because they were able to gradually gain 'real-life' experience, learn proper bedside manner, and gain immediate feedback. One student reflected that "being able to have the four simulations and go from bottom-up was a really good experience (Cass)." Another student mentioned, "Self-insertion gave me the ability to relate with the athlete (Shelley)." Participants had positive perceptions of their experience with the SP because he "provided feedback, and I think that feedback would positively impact my practice (Beth)."

\section{Explanations for the Improvements in Confidence and Competence}

Participants all agreed both their confidence and competence in performing the skill of rectal thermometry improved throughout their simulated experiences. One participant mentioned "I feel confident in knowing how to insert a rectal thermometer and how to prepare a patient physically and mentally...it made me feel like I was prepared to leave the classroom (Cass)." "I've done it on a live patient as well as myself now (Jenny)" and "I could explain the procedure and make the patient at ease (Beth)" were additional comments indicating the participants' changes in both competence and confidence. One participant reflected that she was "prepared to not only go into the field" and perform rectal thermometry but also "teach somebody else (Cass)."

\section{DISCUSSION}

This study identified that athletic training students significantly improved their confidence in identifying and managing lifethreatening heat illness conditions upon completion of four simulated experiences. The Wilcoxon post-hoc test (Table 5) identified statistically significant differences between baseline and post-test 1 for each question item except number one. This indicates after simulation 1, students were already starting to improve in their confidence levels. Survey question items 1, 5, 6, and 8 had statistically significant changes from the pre-test 2 to post-test 2 . Pre-test 2 was administered immediately prior to simulation 2 and post-test 2 was administered immediately following. This indicated the self-insertion experience was effective at improving selfconfidence in administering a rectal thermometer and creating a heat illness action plan. It is also important to note there were statistically significant differences between post-test 3 and post-test 4 for items three and nine. This indicated a significant confidence increase in establishing return to activity guidelines as well as thinking of an emergency plan for heat illness individuals.

While each simulated experience caused significant differences on several of the question items, we can also see throughout the series of four experiences, students' self-confidence scores also improved. As shown in Table 4, we can see the statistically significant improvement over time in confidence scores for the participants across each item regarding heat illness management. Specifically, the survey items addressing self-confidence with recognizing, treating, and preventing heat illness and use of a rectal thermometer went from a baseline score of 4.78-5.78 to 1.11-1.44 at the final post-test. These results indicate the combination of the simulated experiences was of greater impact than any one individual experience.

The results of our study concur with the results of Tivener et al. in that the use of high-fidelity simulation improved the confidence of athletic training students. ${ }^{16}$ Additionally, the implementation of SPs in athletic training education is supported in the literature and further supports our findings that this improves athletic training students' confidence when performing invasive skills. ${ }^{19,21-24}$

The findings of the qualitative interviews agree with previous research that simulated experiences are beneficial and can provide a 'real-life' experience. ${ }^{10,20}$ Our findings also agree with previous literature in that the repeatability of the simulated experiences allowed students the opportunity to reflect and improve on their skills. ${ }^{13}$ Of greatest emphasis, was the students' assurance of their skill competency following the feedback obtained by the SP. Our findings agree with previous literature evaluating occupational 
and physical therapy students' perceptions that patient interactions with SPs improved their self-confidence and prepared them for clinical work. ${ }^{28}$ The findings of this study also indicate that simulation in learning may help athletic training students prepare for their future clinical practice.

\begin{abstract}
Limitations
As with all studies, particularly pilot studies, ours had several limitations. One of the limitations was the sample size. Additionally, throughout the study, retaining participation in the ATSCS survey proved to be a challenge. We only had six participants complete every survey, even with removing the pre-test portion before the third and fourth clinical simulated experiences. Only four students participated in the qualitative semi-structured phone interviews, which may not have been enough to reach data saturation. Additionally, two of those four participants had elected to focus their graduate research on rectal thermometry after participating in these four simulated experiences. Incidentally, these two participants may have had more positive feelings toward rectal thermometry than were reflective of the larger student population. Lastly, the participants in this study were first year professional master's students, so their increase in confidence may have been due to the expected learning that occurred during the first semester of education.
\end{abstract}

\title{
Future Research
}

Future research should be conducted in the area of simulated learning experiences in first- and second-year professional Master of Athletic Training students to gain a better understanding of how we can prepare them to transition to practice. Further research needs to be conducted on a larger participant pool to explain athletic training students' perceptions of how simulated education improves their self-confidence and competence in transferring these skills into clinical practice. Given this was a pilot study, we plan to continue this study with a larger, repeated measures, mixed-methods cohort study that will investigate the effect of highfidelity simulation versus low-fidelity simulation on athletic training students' self-confidence.

\section{CONCLUSION}

This pilot study adds to the growing pool of literature on simulated learning in athletic training education. Our results identify a series of simulated experiences using low to high-fidelity simulation can help improve athletic training students' confidence. Additionally, the findings of the qualitative interviews give beneficial information regarding athletic training students' positive perceptions following rectal thermometry simulations. Students expressed the simulations to be beneficial in gaining a 'real-life' experience that would help them later perform rectal thermometry on actual patients.

Newly credentialed athletic trainers must be confident when performing life-saving techniques. One educational tool that may facilitate the transition to practice and associated confidence level could be simulation. Athletic training education programs should consider the implementation of simulation to accomplish unique patient encounters and better prepare athletic training students to transition to clinical practice. However, future research is still needed to support the recommendation of high-fidelity simulation for teaching rectal thermometry in athletic training education programs.

\section{REFERENCES}

1. Delforge GD, Behnke RS. The history and evolution of athletic training education in the United States. J Athl Train. 1999;34(1):53-61.

2. Weidner TG, Henning JM. Historical perspective of athletic training clinical education. J Athl Train. 2002;37(4 Suppl):S222-S228.

3. Casa DJ, DeMartini JK, Bergeron MF, et al. National Athletic Trainers' Association position statement: exertional heat illnesses. Report. J Athl Train. 2015;(9):986. doi:10.4085/1062-6050-50.9.07

4. Casa DJ, Becker SM, Ganio MS, et al. Validity of devices that assess body temperature during outdoor exercise in the heat. J Athl Train. 2007;42(3):333-342.

5. National Athletic Trainers' Association, Athletic Training Educational Competencies. National Athletic Trainers' Association; 2011.

6. Cavallario JM, Van Lunen BL, Hoch JM, Hoch M, Manspeaker SA, Pribesh SL. Athletic training student core competency implementation during patient encounters. Report. J Athl Train. 2018;(3):282. doi:10.4085/1062-6050-31416

7. Schellhase KC, Plant J, Mazerolle SM. Athletic trainers' attitudes and perceptions regarding exertional heat stroke before and after an educational intervention. Athl Train Educ J. 2017;12(3):179-187. doi:10.4085/1203179

8. 2020 Standards for accreditation of professional athletic training programs crosswalk. Commission on Accreditation of Athletic Training Education Web site. Updated 2020. Accessed September 29, 2020. https://caate.net/wpcontent/uploads/2018/09/2020-Standards-for-Professional-Programs-copyedited-clean.pdf 
9. Griffes LS, Kutz M, Paule-Koba A. Athletic trainer's self-confidence and experience level in managing exertional heat related illnesses. article. Journal of Sports Medicine and Allied Health Sciences: Official Journal of the Ohio Athletic Trainers' Association. 2016;(1)doi:10.25035/jsmahs.02.01.02

10. Walker SE, Weidner TG. Standardized patients provide realistic and worthwhile experiences for athletic training students. Athl Train Educ J. 01/01/ 2010;5(2):77-86.

11. Rosen KR. The history of medical simulation. Article. J Critical Care. 01/01/January 2008 2008;23(2):157-166. doi:10.1016/j.jcrc.2007.12.004

12. Palmer E, Edwards T, Racchini J. High-fidelity simulation meets athletic training education: an innovative collaborative teaching project. Athl Train Educ J. 2014;9(2):96-100.

13. Cuchna JW, Walker SE, Van Lunen BL. Simulated learning best practices within athletic training to support selfefficacy theory. Athl Train Educ J. 2018;13(4):389-389.

14. Paloncy KA. Postdebriefing supervised practice improves clinical performance during simulation-based cardiopulmonary resuscitation encounter. Athl Train Educ J. 2020;15(2):85-92.

15. Doherty-Restrepo JL, Tivener K. Current literature summary: review of high-fidelity simulation in professional education. Athl Train Educ J. 2014;9(4):190-192.

16. Tivener KA, Gloe DS. The effect of high-fidelity cardiopulmonary resuscitation (CPR) simulation on athletic training student knowledge, confidence, emotions, and experiences. Athl Train Educ J. 2015;10(2):103-112.

17. Paloncy KA, Georges L, Liggett AJ. A high-fidelity simulation is effective in improving athletic training students' selfefficacy with emergency cardiovascular care skills. Athl Train Educ J. 2019;14(2):108-116.

18. Doherty-Restrepo JL, Harrelson KE, Swinnie T, Montalvo AM. Does simulation-based training increase athletic training students' clinical confidence and competence in performing a cardiovascular screening? J Allied Health. 2017;46(3):171-177.

19. Armstrong KJ, Jarriel AJ. Standardized patients provide a reliable assessment of athletic training students' clinical skills. Athl Train Educ J. 2016;11(2):88-94. doi:10.4085/110288

20. Gardiner AM, Cuchna JW, Walker SE, Clines S, Welch-Bacon CE, Van Lunen B. Student perceptions of standardized patient use in athletic training education. Athl Train Educ J. 01/01/ 2019;14(1):64-72.

21. Walker $\mathrm{S}$, Weidner T, Armstrong KJ. Standardized patient encounters and individual case-based simulations improve students' confidence and promote reflection: a preliminary study. Athl Train Educ J. 2015;10(2):130-137. doi:10.4085/1002130

22. Walker SE, Weidner TG, Thrasher AB. Small-group standardized patient encounter improves athletic training students' psychosocial intervention and referral skills. Athl Train Educ J. 2016;11(1):38-44. doi:10.4085/110138

23. Armstrong KJ, Jarriel AJ. Standardized patient encounters improved athletic training students' confidence in clinical evaluations. Athl Train Educ J. 2015;10(2):113-121. doi:10.4085/1002113

24. Sims-Koenig KN, Walker SE, Winkelmann ZK, Bush JM, Eberman LE. Translation of standardized patient encounter performance and reflection to clinical practice. Athl Train Educ J. 2019;14(2):117-127. doi:10.4085/1402117

25. Kinslow BL, Schmies H, Armstrong KJ, Martin M. Effective teaching methods for the assessment and treatment of exertional heat illness in athletic training education. Athl Train Educ J. 04//Apr-Jun2019 2019;14(2):128.

26. Miller MB, Macpherson AK, Hynes LM. Athletic therapy students' perceptions of high-fidelity manikin simulation: a pilot study. Athl Train Educ J. 2018;13(2):158-167.

27. Thomas DR. A general inductive approach for analyzing qualitative evaluation data. Am J Eval. 01/01/ 2006;27(2):237246.

28. Giesbrecht EM, Wener PF, Pereira GM. A mixed methods study of student perceptions of using standardized patients for learning and evaluation. article. Adv Med Educ Pract. 2014;(default):241. 